\section{Gibberellic Acid Reverses Effects of Excess Paclobutrazol on Geranium}

\author{
Douglas A. Cox
}

Department of Plant and Soil Sciences, University of Massachusetts, Amherst, MA 01003

Additional index words. Pelargonium $\times$ hortorum, plant growth regulators, PP333

\begin{abstract}
Paclobutrazol (PBZ) was applied to 'Mustang' geranium (Pelargonium $\times$ hortorum L.H. Bailey) as a single growth-medium drench at $0.06 \mathrm{mg}$ a.i./pot or as a single foliar spray at $100 \mathrm{mg} \cdot \mathrm{miter}^{-1}$ when the plants had three to four expanded true leaves (34 days after sowing). At these rates, PBZ caused excessive growth suppression but plants flowered earlier than untreated controls. A single foliar spray of gibberellic acid $\left(\mathrm{GA}_{3}\right.$ ) at $100 \mathrm{mg} \cdot \mathrm{liter}{ }^{-1}$ applied 0 (same day), 7, 14, or 21 days after PBZ reversed the growth suppression caused by PBZ. Plants treated with $\mathrm{GA}_{3} 0$ or 7 days after PBZ were as tall or taller and flowered at the same time as or later than the untreated (no PBZ, no $\mathrm{GA}_{3}$ ) controls. Plants treated with GA, 14 or 21 days after PBZ were shorter and flowered earlier than untreated controls but were taller than plants treated with PBZ alone. Response to $\mathrm{GA}_{3}$ was similar whether $\mathrm{PBZ}$ was applied as a drench or as a spray. Chemical name used: $(+)-\left(\mathbf{R}^{*}, \mathbf{R}^{*}\right)-\beta([4-\mathrm{chlorophenyl}]$ methyl $)-\alpha-(1,1-\mathrm{di}$ methylethyl)-1 $H$-1,2,4-triazole-1-ethanol (paclobutrazol).
\end{abstract}

Geranium growth is readily inhibited by foliar sprays and growth-medium drenches dient. Cox and Keever (1988) found that PBZ spray concentrations $>40 \mathrm{mg} \cdot \mathrm{liter}^{-1}$ and PBZ drenches $>0.015 \mathrm{mg}$ a.i./pot caused excessive and undesirable reductions in height and leaf size of 'Smash Hit' geranium. Foliar sprays of only 6 to $16 \mathrm{mg}$ PBZ/liter are currently recommended for commercial use in controlling geranium height (Sandoz Crop Protection Corp., 1988). The dwarfing effect of PBZ, particularly when applied as a growthmedium drench, is very persistent and, as in the case of marigold, may continue after transplanting into the landscape (Keever and Cox, 1989). Thus, even small errors in the preparation or application of PBZ solutions may result in excessive and long-lasting growth suppression due to the high activity and persistence of PBZ.

Since PBZ is an inhibitor of gibberellin biosynthesis, exogenous applications of $\mathrm{GA}_{3}$ can overcome growth suppression caused by PBZ. Reversal of PBZ effects by $\mathrm{GA}_{3}$ has been reported in marigold (Moore and Schekel, 1985), peach (Casper and Taylor, 1989), poinsettia (Davis et al., 1988), and sunflower (Wample and Culver, 1983). In preliminary experiments (data unpublished), $\mathrm{GA}_{3}$ was effective in reversing the effects of PBZ on geranium. These results suggested that the practical value of $\mathrm{GA}_{3}$ application to PBZ-treated geranium may be limited because time of $\mathrm{GA}_{3}$ application caused different growth, and flowering responses. Therefore, this study was undertaken to further investigate the response of geranium to

Received for publication 11 Sept. 1989. Paper no. 2943 of the Massachusetts Agricultural Experiment Station. The cost of publishing this paper was defrayed in part by the payment of page charges. Under postal regulations, this paper therefore must be hereby marked advertisement solely to indicate this fact. of PBZ at very low levels of active ingre-
$\mathrm{GA}_{3}$ applied at various times following excessive application of PBZ.

Seeds of 'Mustang' geranium were directsown in 0.5-liter pots containing Fafard Mix no. 2 (Conrad Fafard, Springfield, Mass.) on 16 Aug. 1988. Seedlings were thinned to one per pot and fertilized at every watering with $200 \mathrm{mg} \mathrm{N} /$ liter from Peter's 20N-4.4P16.6K Peat-Lite Special (W.R. Grace, Fogelsville, $\mathrm{Pa}$.), beginning 14 days later. Plants were grown in a glasshouse maintained at $\approx 21 / 17 \mathrm{C}$ (day/night) under natural light conditions. PBZ (Bonzi, Sandoz Crop Pro- tection, Chicago) was applied as a single growth-medium drench or foliar spray at rates known to be excessive for geranium (Cox and Keever, 1988) when the-plants had developed three to four expanded true leaves (19 Sept., 34 days after sowing), Drench rate was $0.06 \mathrm{mg}$ a.i./pot $(50 \mathrm{ml} / \mathrm{pot})$ and spray rate was $100 \cdot \mathrm{mgliter}^{-1}(3.2 \pm 0.3 \mathrm{ml} / \mathrm{plant})$. A single foliar spray of $\mathrm{GA}_{3}$ at $100 \mathrm{mg} \cdot 1$ iter (Pro-Gibb, Abbott Labs, North Chicago) was then applied at increasing time intervals following PBZ. Treatments were: untreated control (no PBZ, no $\mathrm{GA}_{3}$ ), PBZ drench alone, PBZ spray alone, and PBZ-treated plants sprayed with $\mathrm{GA}_{3} 0$ (same day), 7, 14, or 21 days after PBZ. Plants 7, 14, and 21 days after PBZ application had five to six, seven to eight, and eight to 10 expanded true leaves, respectively. $\mathrm{GA}_{3}$ spray volumes were 3.2 $\pm 0.3,3.3 \pm 0.6,3.8 \pm 0.8$, and $5.0 \pm$ $1.0 \mathrm{ml} / \mathrm{plant}$ at $0,7,14$, and 21 days, respectively. On day $0, \mathrm{GA}_{3}$ was applied after PBZ spray solution had evaporated $(\approx 2 \mathrm{hr})$. The growth medium was covered during PBZ and $\mathrm{GA}_{3}$ spray applications to protect it from drip. The experiment was a completely randomized design with eight single-plant replicates per treatment. Vegetative plant height (measured from the surface of the growth medium to the uppermost leaf held parallel to growth medium surface), plant width (the average of two width measurements made at right angles to each other), and time to flower (number of days from sowing) were recorded at the opening of the first floret. Size of leaves that developed between the PBZ treatment and the start of $\mathrm{GA}_{3}$ treatments was determined by measuring the area of the leaf at the first flowering node at the conclusion of
Table 1. Effect of $\mathrm{GA}_{3}$ foliar spray following drench and spray applications of PBZ on the growth and flowering of 'Mustang' seed geranium.

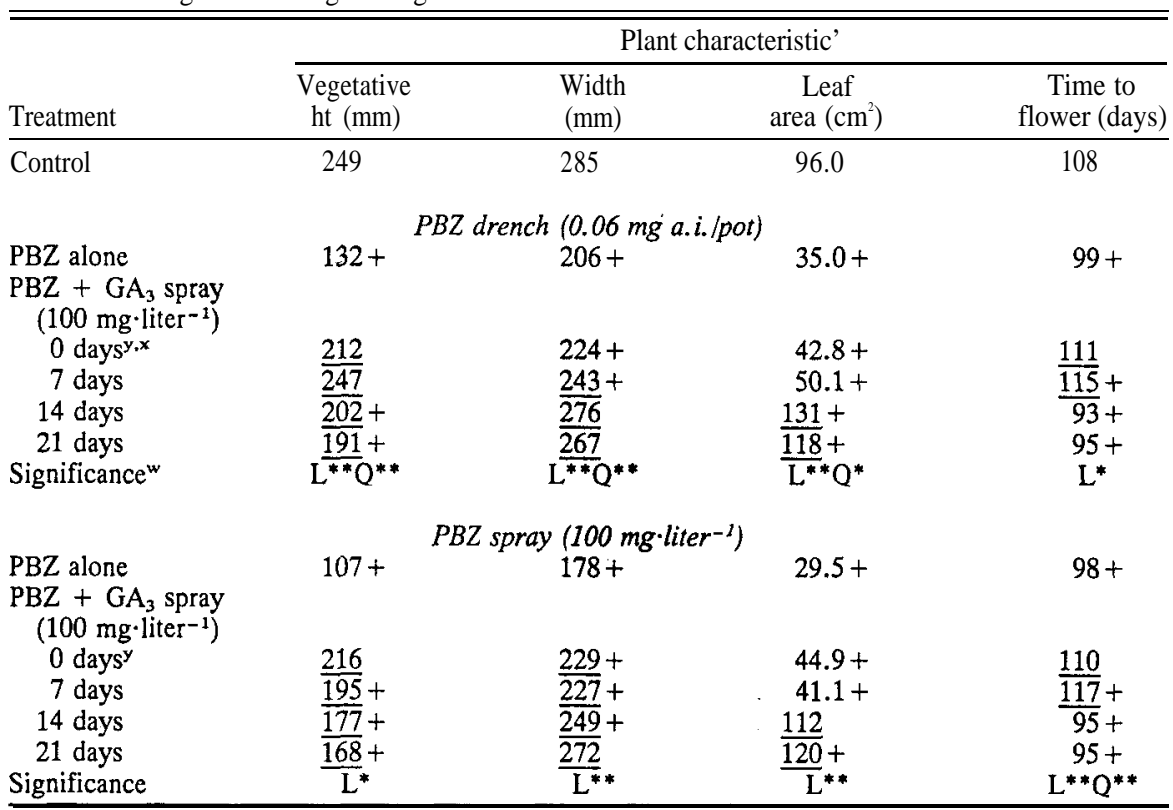

${ }^{2}$ Means followed by this symbol (+) are significantly different from means of untreated control by Dunnett's procedure, $P=0.05$.

${ }^{y}$ Days after PBZ treatment.

${ }^{x}$ Underlined means, within PBZ application method, are significantly different from means of PBZ alone by Dunnett's procedure, $P=0.05$.

"Effects of GA, application time are significant at $P=0.05(*)$ or $0.01(* *)$ and are linear (L) or quadratic (Q). 
the experiment (22 Dec.). Data were subjected to analysis of variance and regression analyses were used to determine significant responses to timing of $\mathrm{GA}_{3}$ treatment.

PBZ alone applied as a drench or spray was effective in reducing height, width, and leaf area (Table 1). As expected, the PBZ drench and spray rates chosen for this experiment were excessive and caused undesirable reductions in height and leaf size. However, plants treated with PBZ flowered $\approx 10$ days earlier than untreated controls. Earlier flowering of geranium treated with PBZ was not observed in our other work (Cox and Keever, 1988), but has been reported by Schekel and Blau (1987).

Growth and flowering responses to $\mathrm{GA}_{3}$ were similar. whether PBZ was applied as a drench or spray, but differed with time of application. The suppression of height and width caused by PBZ was reversed by $\mathrm{GA}_{3}$ treatment regardless of timing (Table 1). However, with later $\mathrm{GA}_{3}$ treatment, plants were shorter and wider at flowering. In several instances, height or width of plants treated with $\mathrm{GA}_{3}$ reached that of untreated controls. Plants drenched with $\mathrm{PBZ}$ and treated with $\mathrm{GA}_{3}$ the same day (0 days) or 7 days later and plants sprayed with $\mathrm{PBZ}$ and $\mathrm{GA}_{3}$ on the same day were as tall at flowering as untreated controls. Plants were as wide as untreated controls at flowering when drenched with $\mathrm{PBZ}$ and treated with $\mathrm{GA}_{3} 14$ or 21 days later or when sprayed with $\mathrm{PBZ}$ and treated with $\mathrm{GA}_{3} 21$ days later.

Leaf area increased with the length of time between PBZ and $\mathrm{GA}_{3}$ treatment (Table 1). However, leaf area of plants treated with $\mathrm{GA}_{3}$ the same day as PBZ or 7 days later was not significantly different from plants treated with PBZ alone. Leaves were as large or larger than. those of untreated controls when $\mathrm{GA}_{3}$ was applied 14 or 21 days after PBZ.

Timing of $\mathrm{GA}_{3}$ sprays affected time to flower (Table 1). $\mathrm{GA}_{3}$ applied the same day as $\mathrm{PBZ}$ or 7 days later delayed flowering compared to PBZ alone, flowering occurred at the same time or later than untreated controls. However, no delay occurred when $\mathrm{GA}_{3}$ was applied 14 or 21 days after PBZ; flowering occurred at the same time as with PBZ alone. Research by Armitage (1986) also showed that exogenously applied $\mathrm{GA}_{3}$ delays flowering of geranium. Flowering was delayed when $\mathrm{GA}_{3}$ was applied before or following flower initiation and $\mathrm{GA}_{3}$ reversed the promotive effect of chlormequat on flowering. In the present study, however, while $\mathrm{GA}_{3}$ applied early in development (three to six true leaves) reversed the effect of PBZ and delayed flowering, later application (seven to 10 true leaves) had no apparent effect on f 1 o w e ring.

$\mathrm{GA}_{3}$ clearly is effective in reversing the effects of excessive PBZ on geranium, but timing of $\mathrm{GA}_{3}$ application is important. The most desirable plants were produced when GA, was applied 14 or 21 days after PBZ (seven to 10 true leaves). These plants flowered earlier and were shorter, but not excessively so, than the untreated controls. However, these effects were accompanied by the development of large leaves that might be considered commercially undesirable. Plants treated with $\mathrm{GA}_{3}$ the same day as PBZ or 7 days later were less desirable than those treated at 14 and 21 days. Height at flowering of these plants equalled or exceeded that of untreated controls, leaf size was not increased compared to PBZ alone, and flowering was delayed. Further evaluation of $\mathrm{GA}_{3}$ treatment at higher and lower PBZ rates is needed to assess the predictability of response. At present, the use of $\mathrm{GA}_{3}$ to reverse the effects of excess PBZ would best be reserved for situations where the potential exists for serious economic loss without treatment.

\section{Literature Cited}

Armitage, A.M. 1986. Chlormequat-induced flowering of hybrid geranium: The influence of gibberellic acid. HortScience 21:116-118.

Casper, J.A. and B.H. Taylor. 1989. Growth and developmentof young 'Loring' peach trees after foliar sprays of paclobutrazol and $\mathrm{GA}_{3}$.
HortScience 24:240-242.

Cox, D.A. and G.J. Keever. 1988. Paclobutrazol inhibits growth of zinnia and geranium. HortScience 23:1029-1030.

Davis, T., R. Walser, and C.F. Williams. 1988. Reverse effects of growth retardants. Greenhouse Grower 6(9):29, 31.

Keever, G.J. and D.A. Cox. 1989. Growth inhibition in marigold following drench and foliarappliedpaclobutrazol. HortScience 24:390.

Moore, T.M. and K.A. Schekel. 1985. GA, temporary reversal of growth retarding effects of paclobutrazol (PP333) on marigold 'First Lady' seedlings. HortScience 20:126. (Abstr.)

Sandoz Crop Protection Corp. 1988. Bonzi. Ornamental growth regulator for use on containergrown flower and bedding plants in greenhouses and shadehouses. Suppl. label 102, Sandoz Crop Protection Corp., Chicago, 111

Schekel, K.A. and S. Blau. 1987. Influence of paclobutrazol and gibberellic acid on flowering of geranium. HortScience 22:1155. (Abstr.)

Wample, R.L. and E.B. Culver: 1983. The influence of paclobutrazol, a new growth regulator, on sunflowers. J. Amer. Soc. Hort. Sci. 108:122-125. 